\title{
Anticancer effect of eupatilin on glioma cells through inhibition of the Notch-1 signaling pathway
}

\author{
YAWEI WANG ${ }^{1 *}$, HONGWEI HOU ${ }^{2 *}$, MING $\mathrm{LI}^{3}$, YANG YANG ${ }^{4}$ and $\mathrm{LAN} \mathrm{SUN}^{3}$ \\ ${ }^{1}$ Department of Electromyography, Tianjin Hospital, Tianjin 300211; ${ }^{2}$ Department of Infection Control, Hebei Chest Hospital, \\ Shijiazhuang, Hebei 050048; ${ }^{3}$ Basic Medical Institution, Shanghai Jiaotong University, Shanghai 200025; \\ ${ }^{4}$ Department of Orthopedics, Tianjin Hospital, Tianjin 300211, P.R. China
}

Received April 13, 2015; Accepted November 19, 2015

DOI: $10.3892 / \mathrm{mmr} .2015 .4671$

\begin{abstract}
Eupatilin, one of the major flavonoids in Artemisia asiatica Nakai (Asteraceae), has been reported to possess antitumor properties. However, thus far there have been no reports regarding the effects of eupatilin on glioma. Therefore, in the current study the effects of eupatilin on glioma and the underlying molecular mechanism were explored. The effect of eupatilin on cell viability was detected by the MTT assay. Cell invasion and migration were performed with Transwell assays and cell apoptosis was determined by flow cytometric analysis. Notch-1 knockdown cells were established by transfection with Notch-1 small interfering RNA (siRNA). The expression levels of Notch-1 were detected by quantitative reverse transcription-polymerase chain reaction and western blotting. The results of the present study indicated that eupatilin exhibits an anticancer effect on glioma cells. Eupatilin inhibited proliferation, reduced cell invasion and migration, and promoted the apoptosis of glioma cells. Additionally, it suppressed Notch-1 expression. Knockdown of Notch-1 by siRNA contributed to the inhibitory effect of eupatilin on proliferation and invasion of glioma cells. In conclusion, eupatilin had an inhibitory effect on proliferation, invasion and migration, and promoted apoptosis of glioma cells through suppression of the Notch-1 signaling pathway. Therefore, eupatilin may have potential as an effective agent for the treatment of glioma.
\end{abstract}

Correspondence to: Dr Yang Yang, Department of Orthopedics, Tianjin Hospital, 406 Jiefang Nan Road, Hexi, Tianjin 300211, P.R. China

E-mail: yangyang-8686@163.com

Dr Lan Sun, Basic Medical Institution, Shanghai Jiaotong University, 227 Chongqin Nan Road, Shanghai 200025, P.R. China

E-mail: sun_lan21@163.com

*Contributed equally

Key words: eupatilin, glioma, proliferation, invasion, Notch-1

\section{Introduction}

Glioma is a common type of brain tumor, accounting for $40-50 \%$ of all intracranial tumors, which vary in size and are highly invasive $(1,2)$. Generally, gliomas are treated via surgery, radiotherapy and chemotherapy; however, it is difficult to remove them completely due to the resistance of tumor cells to radiotherapy. This may lead to a relapse of the residual nidus, resulting in high recurrence, high mortality and low cure rates $(3,4)$. Therefore, it is important to develop novel agents for more effective treatment.

Eupatilin is a pharmacologically active flavonoid extracted from Artemisia asiatica Nakai (Asteraceae) and a primary active component of DA-9601 for mucosal protection $(5,6)$. It has anti-inflammatory properties and is widely used for treatment of gastritis and peptic ulcers (7). Additionally, it has anti-oxidative effects against gastric mucosal damage and may enhance regeneration of damaged mucosa (8). Recently, eupatilin was identified to exhibit an antitumor effect. Cheong et al (9) reported that eupatilin inhibits angiogenesis in gastric cancer cells by blocking the expression of signal transducer and activator of transcription 3, and the expression of vascular endothelial growth factor (VEGF). Park et al (10) determined that eupatilin may be used as a chemopreventive and antimetastatic agent in human gastric cancer. Eupatilin also suppressed the growth of human endometrial cancer cells via arrest of the cell cycle at the G2/M phase through upregulation of p21 (11).

However, to the best of our knowledge, there have been no reports regarding the effects of eupatilin on glioma. Therefore, in the present study aimed to investigate the effects of eupatilin on glioma mechanisms underlying these effects. The results demonstrated that eupatilin has inhibitory effects on proliferation, invasion and migration, and promotes the apoptosis of glioma cells via suppression of the Notch-1 signaling pathway. Additionally, knockdown of Notch-1 enhanced the inhibitory effects of eupatilin on glioma cell growth and invasion.

\section{Materials and methods}

Cell culture. The LN229 and U87MG human glioma cell lines were obtained from the American Type Culture Collection (Manassas, VA, USA) and then cultured at $37^{\circ} \mathrm{C}$ in Dulbecco's modified Eagle's medium(Bio-Rad Laboratories, Inc.,Hercules, 
A

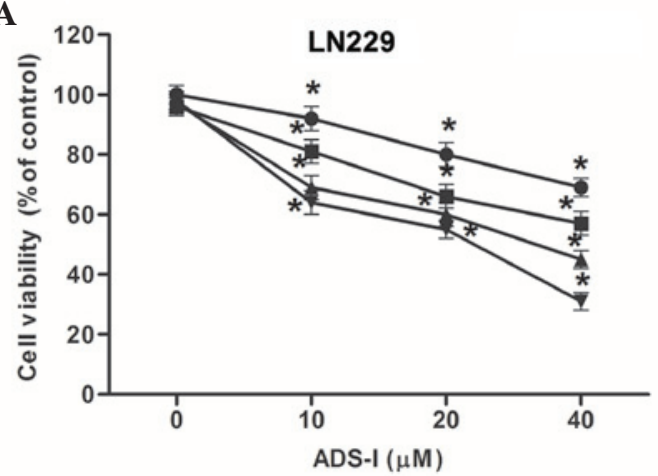

B

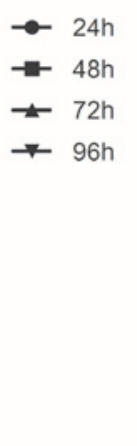

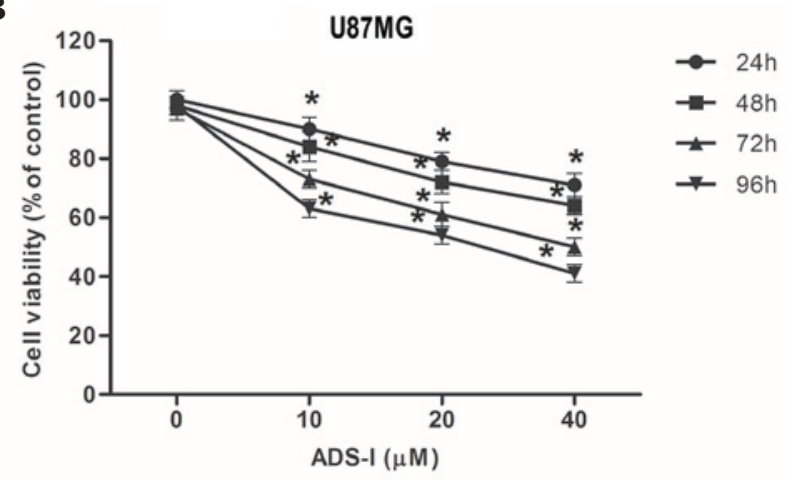

Figure 1. Eupatilin inhibits the viability of glioma cells. Higher concentrations of eupatilin markedly limited the viability of (A) LN229 and (B) U87MG cells. Data are expressed as the mean \pm standard deviation of three independent experiments. ${ }^{*} \mathrm{P}<0.05$ vs. the control group.

CA, USA) supplemented with $10 \%$ fetal bovine serum (FBS; Sigma-Aldrich, St. Louis, MO, USA), $100 \mathrm{U} / \mathrm{ml}$ penicillin (Sigma-Aldrich) and $100 \mathrm{mg} / \mathrm{ml}$ streptomycin (Sigma-Aldrich) in a $5 \% \mathrm{CO}_{2}$ saturated humidity incubator.

Cell viability assay. The LN229 and U87MG cells were seeded in 96-well culture plates at a density of $5 \times 10^{4}$ cells/well. Following $24 \mathrm{~h}$, they were treated with $12.5,25$ or $50 \mu \mathrm{M}$ eupatilin (Sigma-Aldrich) for 24, 48, 72 or $96 \mathrm{~h}$. Control group cells were treated with $0.1 \%$ dimethylsulfoxide (DMSO; Sigma-Aldrich) in culture medium. Subsequent to treatment application, all cells were incubated with 3-(4,5-dimethylthiazol-2-yl)-2,5-diphenyltetrazolium bromide (MTT; Sigma-Aldrich) solution for $24 \mathrm{~h}$ at $37^{\circ} \mathrm{C}$. Then DMSO was added in each well and shaken for $10 \mathrm{~min}$ at room temperature. The optical density was measured with an enzyme-linked immunosorbent assay reader (BioTek Instruments, Inc., Winooski, VT, USA) at a wavelength of $570 \mathrm{~nm}$. Each experiment was performed at least three times.

Cell invasion and migration assays. Cell invasion and migration assays were performed with a Transwell chamber (EMD Millipore, Boston, MA, USA) that was placed in a 24-well plate. The cells were pretreated with $0,12.5,25$ and $50 \mu \mathrm{M}$ eupatilin for $24 \mathrm{~h}$ and then suspended in $50 \mu \mathrm{l}$ serum-free medium (Sigma-Aldrich). The cells were also used for invasion assays, cells at a density of $6 \times 10^{3}$ cells/well were added to the upper chamber and complete medium (Sigma-Aldrich) was added to the lower chamber. The chambers were separated with a polycarbonate membrane was coated with $20 \mu$ l Matrigel (BD Biosciences, San Jose, CA, USA). The cells were then incubated for $36 \mathrm{~h}$ at $37^{\circ} \mathrm{C}$, those remaining in the upper chamber were removed with cotton swabs and the ones on the bottom surface of the membrane were fixed and stained with methanol and Giemsa (Sigma-Aldrich), respectively, and then counted under an optical microscope (x200; CX31; Olympus Corporation, Tokyo, Japan). The migration assay was performed as described above, except that Matrigel was not applied to the membrane.

Cell apoptosis assay. Cell apoptosis was detected with Annexin V-fluorescein isothiocyanate (FITC; Abcam, Cambridge, MA, USA) and propidium iodide (PI; Abcam) staining followed by flow cytometric analysis. Briefly, U87MG cells were seeded in 24-well culture plates at a density of
$4 \times 10^{4}$ cells/well. Eupatilin at concentrations of 0, 12.5, 25 and $50 \mu \mathrm{M}$ was added to the plates after $24 \mathrm{~h}$. The cells were cultured for $48 \mathrm{~h}$ at $37^{\circ} \mathrm{C}$ and then harvested via centrifugation at $1,000 \mathrm{xg}$ for $10 \mathrm{~min}$. The cells were incubated with Annexin V-FITC and PI for $15 \mathrm{~min}$ at room temperature. Apoptosis was analyzed using flow cytometry (FC500; BD Biosciences).

Reverse transcription-quantitative polymerase chain reaction $(R T-q P C R)$. The total RNA was extracted from the eupatilin-treated U87MG cells with TRIzol reagent (Invitrogen; Thermo Fisher Scientific, Inc., Waltham, MA, USA) in accordance with the manufacturer's protocol. cDNA synthesis was conducted using $5 \mu \mathrm{g}$ of the total RNA with M-MuLV reverse transcriptase (Clontech Laboratories, Inc., Palo Alto, CA, USA). The genes of interest were amplified with the following primers: Forward: 5'-TCAGCGGGATCCACTGTGAG-3' and reverse: 5'-ACACAGGCAGGTGAACGAGTTG-3' for Notch-1; and forward: 5'-CTCCATCCTGGCCTCGCTGT-3' and reverse: 5'-GCTGTCACCTTCACCGTTCC-3' for $\beta$-actin. $\beta$-actin was used as a control. The PCR was run for 30 cycles at $94^{\circ} \mathrm{C}$ (denaturation) for $30 \mathrm{sec}$, at $55^{\circ} \mathrm{C}$ (annealing) for $30 \mathrm{sec}$ and at $72^{\circ} \mathrm{C}$ (extension) for $20 \mathrm{sec}$. The experiment was performed for three times. The data obtained was calculated using the comparative $\mathrm{Cq}$ method $\left(2^{-\Delta \Delta \mathrm{Cq})}\right.$ as previously described (12).

Western blot analysis. The U87MG cells were treated with $0,12.5,25$ and $50 \mu \mathrm{M}$ eupatilin for $24 \mathrm{~h}$ and then immersed in a lysis buffer containing $40 \mathrm{mmol} / \mathrm{l}$ Tris- $\mathrm{HCl}$, $1 \mathrm{mmol} / 1$ EDTA, $150 \mathrm{mmol} / 1 \mathrm{KCl}, 100 \mathrm{mmol} / 1 \mathrm{NaVO}_{3}$, $1 \%$ Triton $\mathrm{X}-100$, and $1 \mathrm{mmol} / \mathrm{l}$ phenylmethylsulfonyl fluoride (pH 7.5). The protein was separated by $10 \%$ sodium dodecyl sulphate-polyacrylamide gel electrophoresis (Sigma-Aldrich) and then transferred onto nitrocellulose membranes (Bio-Rad Laboratories, Inc.). The membranes were treated with 5\% non-fat milk in Tris-buffered saline (TBS) at room temperature for $1 \mathrm{~h}$ and then incubated overnight at $4^{\circ} \mathrm{C}$ with primary mouse monoclonal anti-human Notch-1 (1:1,500; Santa Cruz Biotechnology, Inc., Dallas, TX, USA; cat. no. sc-373944) or $\beta$-actin $(1: 1,000$; Santa Cruz Biotechnology, Inc.; cat. no. sc-8432). The membranes were then washed three times with TBS and Tween-20 (TBST) for $10 \mathrm{~min}$ at room temperature. Subsequently, the membranes were incubated with a bovine anti-mouse horseradish peroxidase-conjugated 
A

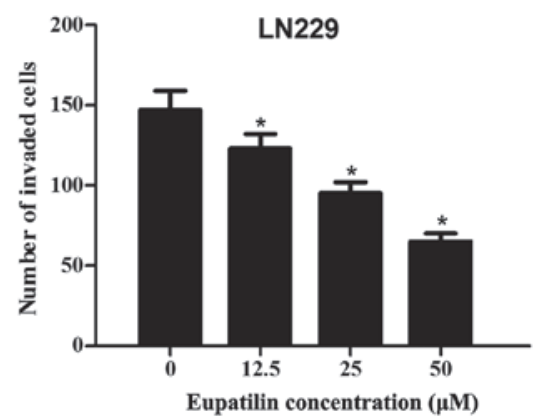

C

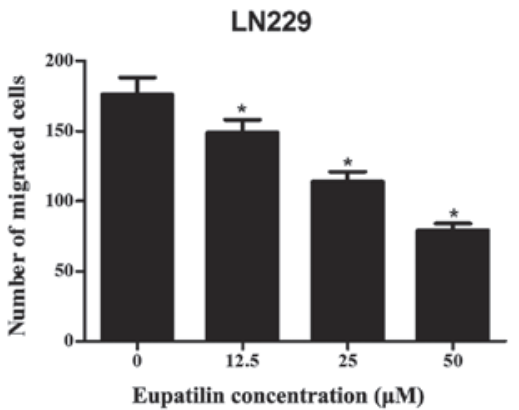

B

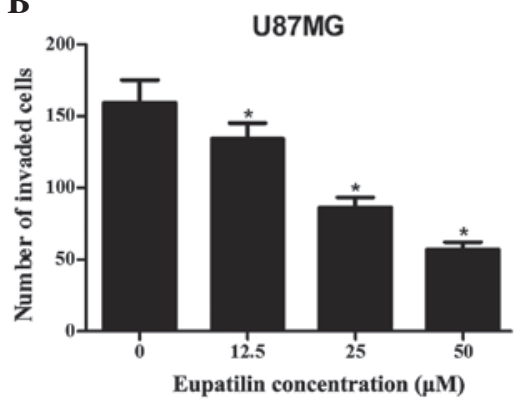

D

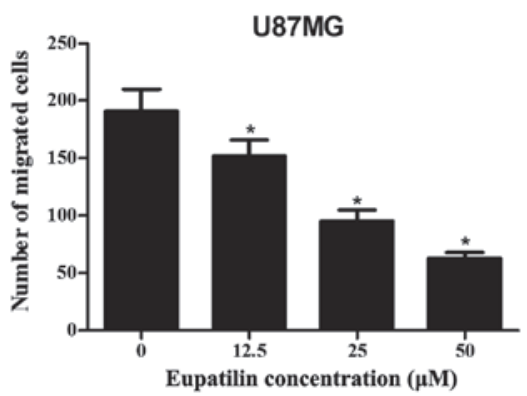

Figure 2. Eupatilin inhibits the invasion and migration of glioma cells. The number of invaded (A) LN229 and (B) U87MG cells following treatment with eupatilin. The number of (C) LN229 and (D) U87MG cells migrating through the membrane. Data are presented as the mean \pm standard deviation. ${ }^{*} \mathrm{P}<0.05$ vs. the control group.

A
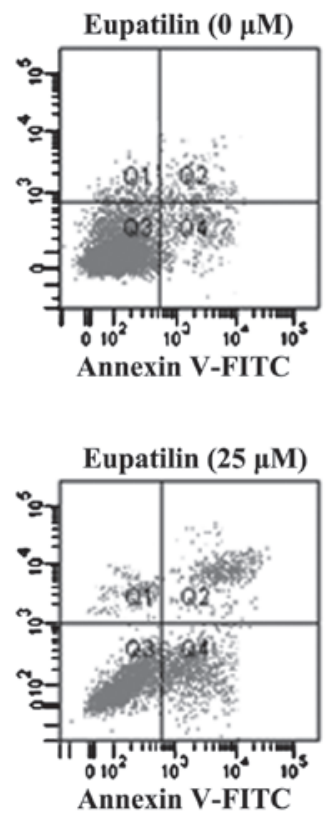

Eupatilin $(12.5 \mu \mathrm{M})$

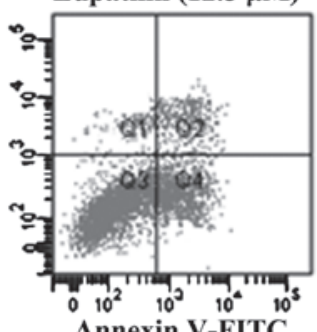

Annexin V-FITC

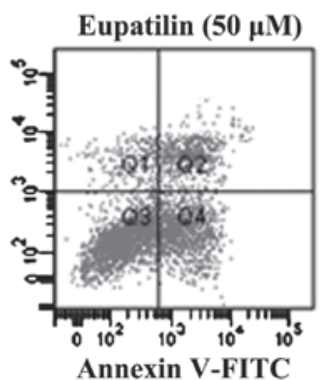

$\mathbf{B}$

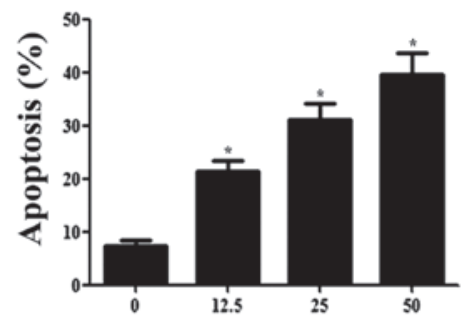

Eupatilin concentration $(\mu \mathrm{M})$

Figure 3. Eupatilin promotes the apoptosis of glioma cells. (A) U87MG cells were treated with $12.5,25$ and $50 \mu \mathrm{M}$ eupatilin for $24 \mathrm{~h}$, and cell apoptosis was examined by flow cytometric analysis. (B) Columns present mean data obtained from three independent experiments. Data are expressed as mean \pm standard deviation. ${ }^{*} \mathrm{P}<0.05$ vs. the control group. FITC, fluorescein isothiocyanate.

secondary antibody (1:3,000; Santa Cruz Biotechnology, Inc.; cat. no. sc-2370) for $1 \mathrm{~h}$ at room temperature and then washed three times for $10 \mathrm{~min}$ with TBST and once with TBS. Immunoreactive bands were detected by enhanced chemiluminescence (GE Healthcare Life Sciences, Freiburg, Germany). The optical densities of the bands were quantified using a Gel-Pro Analyzer, version 4.0 (Media Cybernetics, Inc, Rockville, MD, USA).
Small interfering RNA (siRNA)-Notch-1 and cell transfection. The siRNA sequences were as follows: Sense 5'-ACGAAG AACAGAAGCACAAAGGCGG-3' and antisense 5'-CCG CCUUUGUGCUUCUGUUCUUCGU-3' for Notch-1; and sense 5'-UUCUCCGAACGUGUCACGUTT-3' and antisense 5'-ACGUGACACGUUCGGAGAATT-3' for scramble control. Prior to transduction (24 h), U87MG cells, at a density of $5 \times 10^{4}$ cells/well, were seeded into 6-well plates and then 
A

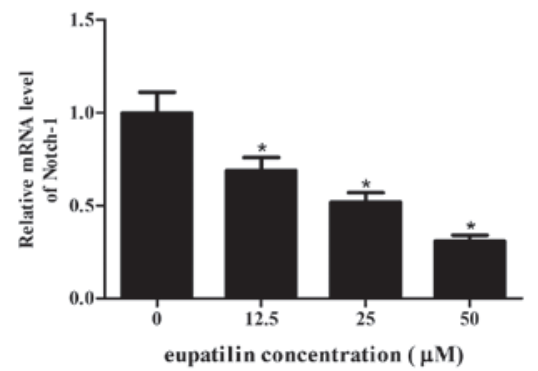

B

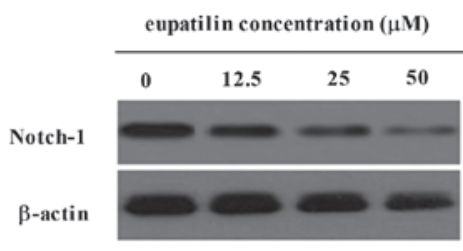

C

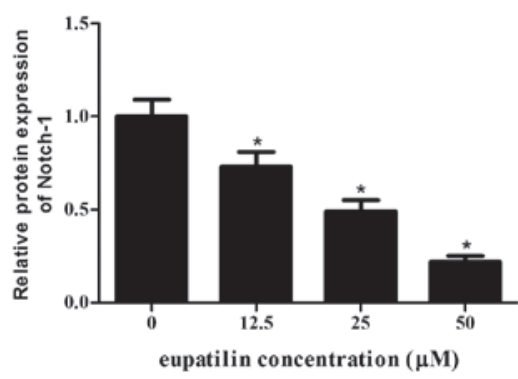

Figure 4. Eupatilin reduces Notch-1 expression in glioma cells. The mRNA and protein expression levels of Notch-1 in U87MG cells were assessed using (A) reverse transcription-quantitative polymerase chain reaction and (B) western blot analysis, respectively. Expression levels of Notch-1 mRNA and protein in eupatilin treatment groups were significantly lower compared with the control group. (C) Quantification of the western blot. Data are expressed as the mean \pm standard deviation of three separate experiments. ${ }^{*} \mathrm{P}<0.05$ vs. the control group.

A

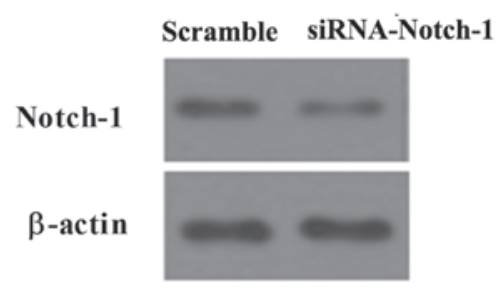

B

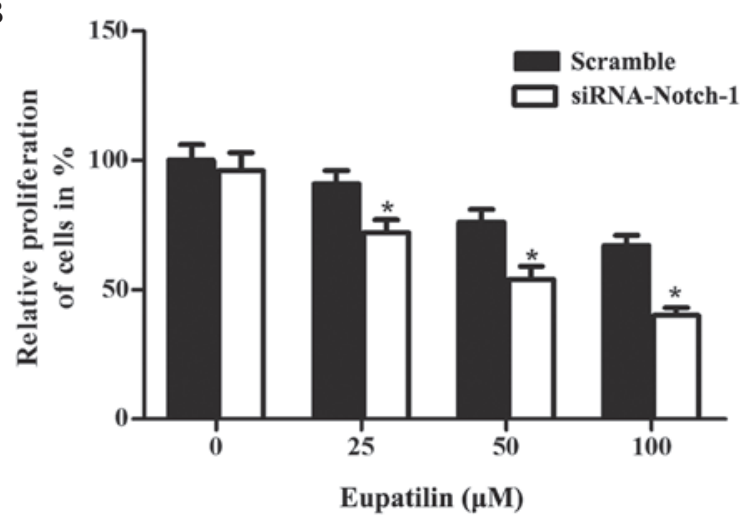

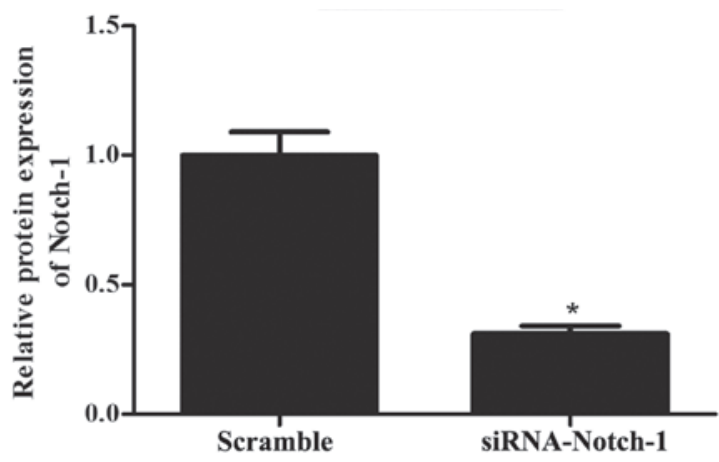

C

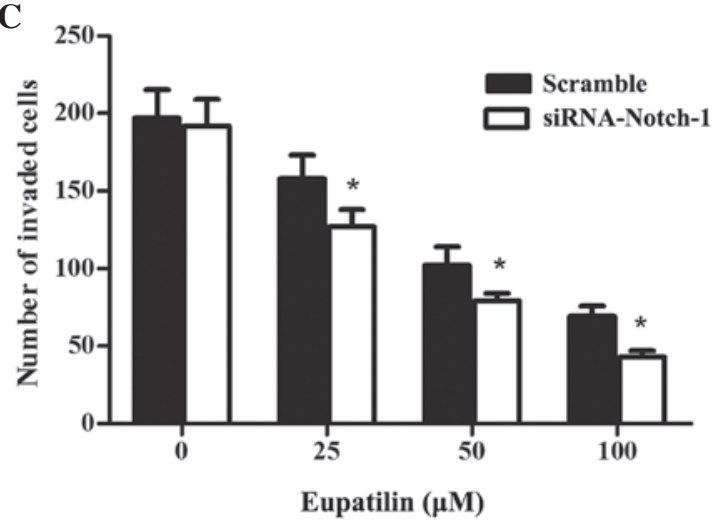

Figure 5. Downregulation of Notch-1 by siRNA potentiated eupatilin-induced proliferation and invasion inhibition in glioma cells. (A) Notch-1 protein expression level in the siRNA-Notch-1-transfected group was significantly reduced compared with the control group as determined by western blot analysis. siRNA-Notch-1 enhanced eupatilin-inhibited (B) proliferation and (C) invasion of U87MG cells. ${ }^{*} \mathrm{P}<0.05$ vs. the scramble control. siRNA, small interfering RNA.

cultured in $2 \mathrm{ml}$ basic culture medium containing 5\% FBS until the cells were $70 \%$ confluent. The cells were then transfected with Notch-1 siRNA or the scramble control siRNA, using Lipofectamine 2000 (Invitrogen; Thermo Fisher Scientific, Inc.) according to the protocol described in Côté et al (13). Subsequently, the transfected cells were treated with $0,12.5$, 25 and $50 \mu \mathrm{M}$ eupatilin for $48 \mathrm{~h}$.

Statistical analysis. All experiments were performed at least three times and the data were expressed as the mean \pm standard deviation. The differences between the sample means were compared using one-way analysis of variance using SPSS, version 19 (IBM SPSS, Armonk, NY, USA). P<0.05 was considered to indicate a statistically significant difference.

\section{Results}

Eupatilin inhibits the viability of glioma cells. The effect of eupatilin on the viability of glioma cells was investigated using an MTT assay. As demonstrated by Fig. 1, higher doses of eupatilin significantly reduced LN229 and U87MG cell viability $(\mathrm{P}<0.05$; Fig. $1 \mathrm{~A}$ and $\mathrm{B})$ compared with the control group. Additionally, exposing the cells to eupatilin for a longer time period enhanced its effect on cell viability. These observations indicate that eupatilin may inhibit the viability of LN229 and U87MG cells.

Eupatilin inhibits the invasion and migration of glioma cells. The effect of eupatilin on invasion and migration of glioma 
cells was also determined. First, we examined the effect of eupatilin on invasion of glioma cells using a transwell chamber with Matrigel. As demonstrated in Fig. 2A and B, the treatment of LN229 and U87MG cells with 0, 12.5, 25 and $50 \mu \mathrm{M}$ eupatilin for $24 \mathrm{~h}$ resulted in inhibition of cell invasion in a dose-dependent manner. Subsequently, the effect of eupatilin on migration of glioma cells was also investigated using a Transwell chamber without Martrigel being applied. Fig. 2C and D demonstrates that the number of eupatilin-treated cells that migrated into the lower chamber was significantly reduced, compared with the control group $(\mathrm{P}<0.05)$.

Eupatilin promotes the apoptosis of glioma cells. Following treatment with eupatilin for $48 \mathrm{~h}$, apoptosis of U87MG cells stained with Annexin V-FITC and PI was determined by flow cytometric analysis. As presented in Fig. 3, the apoptotic rate of the cells in the eupatilin treatment group was significantly higher than in the control group, indicating that eupatilin induced the apoptosis of glioma cells $(\mathrm{P}<0.05)$.

Eupatilin reduces Notch-1 expression in glioma cells. Notch-1 is a transmembrane receptor which is often important for the proliferation and invasion of tumor cells (14). The current study determined how eupatilin affects Notch-1 expression using RT-PCR and western blot analysis. The protein and mRNA expression levels of Notch-1 following treatment with different concentrations of eupatilin were significantly reduced compared with the control group in a dose-dependent manner ( $\mathrm{P}<0.05$; Fig. 4). Therefore, eupatilin may suppress Notch-1 expression in glioma cells.

Downregulation of Notch-1 by siRNA potentiates the eupatilin-induced inhibition of proliferation and invasion of glioma cells. In order to further examine the effect of Notch-1 glioma cells, Notch-1 was downregulated in U87MG cells using siRNA. The transfected cells were treated with eupatilin of different concentrations for $48 \mathrm{~h}$. The protein expression levels of Notch-1 were detected by western blot analysis (Fig. 5A). The combination of Notch-1 siRNA and eupatilin treatment led to inhibition of proliferation and invasion of glioma cells to a greater extent than that observed following treatment with eupatilin only (Fig. 5B and C).

\section{Discussion}

The current study determined that eupatilin has an anticancer effect on glioma cells. This was demonstrated by the inhibition of cell viability, decreased migration and proliferation, and increased apoptosis of glioma cells. Additionally, eupatilin suppressed Notch-1 expression and when combined with a knockdown of Notch-1 by siRNA its anticancer effect was increased.

Cell proliferation is important for cell survival and it is also an essential biological feature of tumor formation. Therefore, one aim of tumor treatment is to inhibit tumor proliferation. The present study determined that eupatilin may suppress the proliferation of viable glioma cells in a dose-dependent manner. Consistent with these results, Son et al (15) reported that eupatilin also exhibited an inhibitory effect on the proliferation of human aortic smooth muscle cells. In addition, eupatilin inhibited the proliferation of ras-transformed human breast epithelial cells (16).

Reducing metastasis may also be a promising method for tumor treatment, as a high rate of metastasis often results in a poor prognosis. In order to reduce metastasis, invasion and migration of tumor cells should be inhibited. The present study aimed to observe the effect of eupatilin on invasion and migration of glioma cells using Transwell assays. Overall, eupatilin decreased the migration and invasion abilities of glioma cells in a dose-dependent manner. These results were consistent with previous studies that focused on gastric and aortic cells $(10,15)$. Therefore, eupatilin may be used to suppress the invasion and migration of glioma cells.

Triggering apoptosis in cancer cells may be an important method for treating cancer $(17,18)$. Seo and Surh (19) revealed that eupatilin may induce apoptosis in human promyelocytic leukemia cells. In addition, Kim et al (20) demonstrated that eupatilin may induce apoptosis in human gastric cancer cells. In accordance with these studies, the present study identified that eupatilin may promote apoptosis in glioma cells in a concentration-dependent manner.

The Notch signaling pathway is important for regulating cell proliferation and apoptosis $(21,22)$. It has been reported that the Notch signaling pathway has a context-dependent function in tumorigenesis, either acting in an antiproliferative or oncogenic manner (23). For example, the Notch gene suppresses proliferation and induces apoptosis in certain tumor cells, such as lung adenocarcinoma and hepatocellular carcinoma cells; however, it functions as an oncogene in the majority of solid tumors, such as glioma and breast cancer (24-27). For example, Wang et al (28) reported that the Notch signaling pathway contributes to glioma growth. Additionally, it has been demonstrated that the Notch signaling pathway is important in the development of glioma and may regulate proliferation of glioma cells (29). There is growing evidence that Notch-1 may affect the growth and invasion of glioma cells and its downregulation may inhibit proliferation and promote apoptosis $(26,30,31)$. The present study determined that eupatilin may reduce Notch-1 expression in glioma cells. When this was combined with knockdown of Notch-1 by siRNA the inhibitory effect on glioma cell proliferation and invasion was greater. These results suggested that eupatilin inhibited proliferation, invasion and migration, and induced apoptosis through the suppression of the Notch-1 signaling pathway in glioma cells.

In conclusion, eupatilin exhibited an inhibitory effect on the proliferation, invasion and migration of glioma cells, in addition to promoting apoptosis via suppression of the Notch-1 signaling pathway. Therefore, eupatilin may be a potential agent for treatment of glioma.

\section{References}

1. Jovčevska I, Kočevar N and Komel R: Glioma and glioblastoma - how much do we (not) know? Mol Clin Oncol 1: 935-941, 2013.

2. Partap S and Fisher PG: Update on new treatments and developments in childhood brain tumors. Curr Opin Pediatr 19: 670-674, 2007.

3. Van Meir EG, Hadjipanayis CG, Norden AD, Shu HK, Wen PY and Olson JJ: Exciting new advances in neuro-oncology: The avenue to a cure for malignant glioma. CA Cancer J Clin 60: 166-193, 2010. 
4. Yaneva MP, Semerdjieva ML, Radev LR and Vlaikova MI: Postoperative chemo-radiotherapy with temodal in patients with glioblastoma multiforme - survival rates and prognostic factors. Folia Med (Plovdiv) 52: 26-33, 2010.

5. Jung J, Ko SH, Yoo Y, Lee JY, Kim YJ, Choi SM, Kang KK, Yoon $\mathrm{HJ}$, Kim $\mathrm{H}$, Youn $\mathrm{J}$ and $\mathrm{Kim} \mathrm{JM}$ : 5, 7-Dihydroxy-3,4,6-trimethoxyflavone inhibits intercellular adhesion molecule 1 and vascular cell adhesion molecule 1 via the Akt and nuclear factor- $\kappa \mathrm{B}$-dependent pathway, leading to suppression of adhesion of monocytes and eosinophils to bronchial epithelial cells. Immunology 137: 98-113, 2012.

6. Oh TY, Ahn GJ, Choi SM, Ahn BO and Kim WB: Increased susceptibility of ethanol-treated gastric mucosa to naproxen and its inhibition by DA-9601, an Artemisia asiatica extract. World J Gastroenterol 11: 7450-7456, 2005.

7. Choi EJ, Lee S, Chae JR, Lee H-S, Jun CD and Kim SH Eupatilin inhibits lipopolysaccharide-induced expression of inflammatory mediators in macrophages. Life Sci 88 1121-1126, 2011

8. Oh TY, Lee JS, Ahn BO, Cho H, Kim WB, Kim YB, Surh YJ, Cho SW, Lee KM and Hahm KB: Oxidative stress is more important than acid in the pathogenesis of reflux oesophagitis in rats. Gut 49: 364-371, 2001.

9. Cheong JH, Hong SY, Zheng Y and Noh SH: Eupatilin inhibits gastric cancer cell growth by blocking STAT3-mediated VEGF expression. J Gastric Cancer 11: 16-22, 2011.

10. Park BB, Yoon J, Kim E, Choi J, Won Y, Choi J and Lee YY: Inhibitory effects of eupatilin on tumor invasion of human gastric cancer MKN-1 cells. Tumour Biol 34: 875-885, 2013.

11. Cho JH, Lee JG, Yang YI, Kim JH, Ahn JH, Baek NI, Lee KT and Choi J-H: Eupatilin, a dietary flavonoid, induces G2/M cell cycle arrest in human endometrial cancer cells. Food Chem Toxicol 49: 1737-1744, 2011.

12. Livak KJ and Schmittgen TD: Analysis of relative gene expression data using real-time quantitative PCR and the 2(- $\Delta \Delta \mathrm{C}(\mathrm{T}))$ method. Methods 25: 402-408, 2001.

13. Côté MC, Lavoie JR, Houle F, Poirier A, Rousseau S and Huot J: Regulation of vascular endothelial growth factor-induced endothelial cell migration by LIM kinase 1-mediated phosphorylation of annexin 1. J Biol Chem 285: 8013-8021, 2010.

14. Teodorczyk M and Schmidt MH: Notching on cancer's door: Notch signaling in brain tumors. Front Oncol 4: 341-354, 2015.

15. Son JE, Lee E, Seo SG, Lee J, Kim JE, Kim J, Lee KW and Lee HJ: Eupatilin, a major flavonoid of Artemisia, attenuates aortic smooth muscle cell proliferation and migration by inhibiting PI3K, MKK3/6, and MKK4 activities. Planta Med 79: 1009-1016, 2013.

16. Kim DH, Na HK, Oh TY, Shin CY and Surh YJ: Eupatilin inhibits proliferation of ras-transformed human breast epithelial (MCF-10A-ras) cells. J Environ Pathol Toxicol Oncol 24: 251-259, 2005.
17. Kang N, Zhang J-H, Qiu F, Tashiro S, Onodera S and Ikejima T: Inhibition of EGFR signaling augments oridonin-induced apoptosis in human laryngeal cancer cells via enhancing oxidative stress coincident with activation of both the intrinsic and extrinsic apoptotic pathways. Cancer Lett 294: 147-158, 2010.

18. Strasser A, Cory S and Adams JM: Deciphering the rules of programmed cell death to improve therapy of cancer and other diseases. EMBO J 30: 3667-3683, 2011.

19. Seo HJ and Surh YJ: Eupatilin, a pharmacologically active flavone derived from Artemisia plants, induces apoptosis in human promyelocytic leukemia cells. Mutat Res 496: 191-198, 2001.

20. Kim MJ, Kim DH, Na HK, Oh TY, Shin CY and Surh Ph D Professor YJ: Eupatilin, a pharmacologically active flavone derived from Artemisia plants, induces apoptosis in human gastric cancer (AGS) cells. J Environ Pathol Toxicol Oncol 24: 261-269, 2005.

21. Ye QF, Zhang YC, Peng XQ, Long Z, Ming YZ and He LY: Silencing Notch-1 induces apoptosis and increases the chemosensitivity of prostate cancer cells to docetaxel through Bcl-2 and Bax. Oncol Lett 3: 879-884, 2012

22. Kopan R and Ilagan MX: The canonical Notch signaling pathway: Unfolding the activation mechanism. Cell 137: 216-233, 2009.

23. Joutel A and Tournier-Lasserve E: Notch signalling pathway and human diseases. Semin Cell Dev Biol 9: 619-625, 1998.

24. Zheng Q, Qin H, Zhang H, Li J, Hou L, Wang H, Zhang X, Zhang S, Feng L, Liang Y, et al: Notch signaling inhibits growth of the human lung adenocarcinoma cell line A549. Oncol Rep 17: 847-852, 2007.

25. Wang $M$, Xue L, Cao Q, Lin Y, Ding Y, Yang P and Che L: Expression of Notch1, Jagged1 and beta-catenin and their clinicopathological significance in hepatocellular carcinoma. Neoplasma 56: 533-541, 2009.

26. Purow BW, Haque RM, Noel MW, Su Q, Burdick MJ, Lee J, Sundaresan T, Pastorino S, Park JK, Mikolaenko I, et al: Expression of Notch-1 and its ligands, Delta-like-1 and Jagged-1, is critical for glioma cell survival and proliferation. Cancer Res 65: 2353-2363, 2005.

27. Reedijk M, Odorcic S, Chang L, Zhang H, Miller N, McCready DR, Lockwood G and Egan SE: High-level coexpression of JAG1 and NOTCH1 is observed in human breast cancer and is associated with poor overall survival. Cancer Res 65: 8530-8537, 2005.

28. Wang J, Wang C, Meng Q, Li S, Sun X, Bo Y and Yao W: siRNA targeting Notch-1 decreases glioma stem cell proliferation and tumor growth. Mol Biol Rep 39: 2497-2503, 2012.

29. Xing ZY, Sun LG and Guo WJ: Elevated expression of Notch-1 and EGFR induced apoptosis in glioblastoma multiforme patients. Clin Neurol Neurosurg 131: 54-58, 2015.

30. Zhou ZD, Kumari U, Xiao ZC and Tan EK: Notch as a molecular switch in neural stem cells. IUBMB Life 62: 618-623, 2010

31. Zhao N, Guo Y, Zhang M, Lin L and Zheng Z: Akt-mTOR signaling is involved in Notch-1-mediated glioma cell survival and proliferation. Oncol Rep 23: 1443-1447, 2010. 